\title{
Effects of the Health Transformation Plan on caesarean section rate in the Islamic Republic of Iran: an interrupted time series
}

Arash Rashidian, ${ }^{1,2}$ Ghobad Moradi, ${ }^{3}$ Amirhossein Takian,,${ }^{1,4}$ Minoo Alipouri Sakha, ${ }^{1}$ Sedighe Salavati, ${ }^{1}$ Obeidollah Faraji ${ }^{3}$ and Bakhtiar Piroozi ${ }^{3}$

${ }^{1}$ Department of Health Management and Economics, School of Public Health, Tehran University of Medical Sciences, Tehran, Islamic Republic of Iran. ${ }^{2}$ World Health Organization Regional Office for the Eastern Mediterranean, Cairo, Egypt. ${ }^{3}$ Social Determinants of Health Research Center, Research Institute for Health Development, Kurdistan University of Medical Sciences, Sanandaj, Islamic Republic of Iran. ${ }^{4}$ College of Health and Life Sciences, Brunel University, London, United Kingdom. (Correspondence to: Bakhtiar Piroozi: bpiroozi@gmail.com).

\begin{abstract}
Background: In recent decades, the rate of caesarian section (C-section) has increased in the Islamic Republic of Iran. A reform in the Iranian health system - the Health Transformation Plan (HTP) - was launched in 2014 in which one of the objectives of HTP is decreasing the rate of C-section.

Aims: This study aimed to assess the effects of the Health Transformation Plan (HTP) on the C-section rate in the Islamic Republic of Iran.

Methods: This study was an interrupted time series analysis that used segmented regression analysis to assess the immediate and long-term effects of the HTP on C-section rate in two groups of hospitals affiliated and not affiliated to the Ministry of Health and Medical Education (MoHME) in Kurdistan province. Study samples were selected using the data on monthly C-section rate collected over a period of four years.

Results: We observed significant decreases in C-section rate immediately after the HTP in both groups of hospitals by 0.0629 and 0.0013 , respectively $(P<0.05)$. In the long run, we observed no significant decrease in the regression slope of $\mathrm{C}$-section rate in both groups.
\end{abstract}

Conclusions: The implementation of HTP decreased the C-section rate. However, the reduction does not meet expectations.

Keywords: Health system reform, caesarean section, financial incentive, Iran

Citation: Rashidian A; Moradi G; Takian A; Alipouri Sakha M; Salavati S; Faraji O; et al. Effects of the Health Transformation Plan on caesarean section rate in the Islamic Republic of Iran: an interrupted time series. East Mediterr Health J. 2019;25(4):254-261. https://doi.org/10.26719/emhj.18.044

Received: 11/06/17; accepted: 23/10/17

Copyright ( C World Health Organization (WHO) 2019. Some rights reserved. This work is available under the CC BY-NC-SA 3.0 IGO license (https:// creativecommons.org/licenses/by-nc-sa/3.o/igo).

\section{Introduction}

In recent years, the Islamic Republic of Iran, like many countries of the world, has observed an increase in the rate of caesarian section (C-section) (1-3). Between 2000 and 2013 the C-section rate increased from $35 \%$ to $56.1 \%$ $(1,4,5)$, while the acceptable rate of C-section recommended by the World Health Organization (WHO) is between $10 \%$ and $15 \%(4,6)$. The rapid increase in the rate of C-section can be attributed to both clinical and non-clinical factors. Among the non-clinical factors that can affect a physician's decision for C-section are training and fear of malpractice claims (6-9), as well as opportunity for higher income (10). On the other hand, the mother's level of education, ethnicity, income, and insurance status are also contributing factors $(11,12)$.

The growing number of unnecessary C-sections can result in many problems; for example, it not only increases healthcare costs but also augments the risk of mortality and morbidity in mothers and neonates, which in turn affects public health (13). In recent years, in order to reduce the rate of C-sections in the Islamic Republic of Iran, the Ministry of Health and Medical Education (MoHME) has suggested a number of reforms. For instance, it is recommended to change the educational curriculum of midwives and the content of obstetric residency programmes as well as revise their postgraduate training courses. It is also suggested to develop guidelines for outpatient and inpatient obstetrical emergencies and even make changes to medical legislation. However, the $\mathrm{C}$-section rate has still not declined (5).

Previous studies have shown that cost variation is another factor that affects the decision regarding the mode of delivery. As C-section is financially more rewarding and requires less time per birth than a vaginal delivery, physicians are motivated to over-utilize C-section (14-17). Thus, changes in the reimbursement system with respect to the cost of delivery may change the decision of physicians and mothers regarding the mode of delivery. In recent years in the Islamic Republic of Iran, the mean cost of C-section delivery has been almost twice as much as that of vaginal delivery. According to health experts, it is one of the reasons that motivates obstetricians and gynaecologists to perform C-section without any indication (18).

\section{An overview of the Iranian healthcare system}

In the Islamic Republic of Iran, public, private, quasi-public and charity sectors provide healthcare services. Primary healthcare services are provided by the government 
through an extensive healthcare network and are offered free of charge. Over $93 \%$ of second and third level healthcare services are provided by clinics, centres and hospitals affiliated to MoHME, with other centres affiliated to the Social Security Organization (SSO) and the private sector. Centres affiliated to MoHME and SSO, respectively, are classified as public sector and quasi-public sector. SSO not only provides health services, but is also one of the largest insurance agencies in the country. Social security insurance holders who attended the centres affiliated to SSO receive the majority of services free of charge, but other insurance holders have to pay a portion of the costs $(19,20)$.

The Islamic Republic of Iran has three main insurance organizations including the Iranian Health Insurance Organization (IHIO), SSO, and Armed Forces Insurance Organization (AFIO). IHIO and SSO have multiple insurance schemes, which cover both compulsory and optional insurances, while the AFIO schemes are compulsory. The universities of medical sciences in every province are responsible for monitoring all healthcare centres (public or not) in the province; in addition, the hospitals affiliated to MoHME in each province are under the direct supervision of the university (19). In the Islamic Republic of Iran, about $95 \%$ of deliveries occur in hospitals (20), with 557 hospitals affiliated to MoHME, 337 hospitals to the private sector, and 70 hospitals to SSO (19).

\section{Iranian Health Transformation Plan}

In the Islamic Republic of Iran a series of health reforms (under the title of Health Transformation Plan) were implemented over three phases that started in 2014. The first phase consisted of eight packages and came into force 5 May 2014 in all hospitals affiliated to MoHME (university hospitals) (21). The Natural Delivery Promotion Package encourages mothers to have a vaginal birth and natural childbirth in hospitals affiliated to MoHME is free of charge. In addition, during this phase to motivate obstetricians, gynaecologists and midwives to encourage vaginal delivery, the promotional tariff of $30 \mathrm{~K}(\mathrm{~K}$ is the fee of a surgical operation which in 2013 was set at 88000 Rials for the public sector and social security (quasi-public) and 380000 Rials for the private sector) for natural childbirth (added to the tariff of natural delivery), was considered for all deliveries performed in hospitals affiliated to MoHME within a time interval from 5 May 2014 to 23 September 2014. In case of vaginal delivery under the supervision of a full-time gynaecologist and obstetrician, the inventive was shared as follows: $70 \%$ for physicians, $10 \%$ for midwifes $10 \%$ for staff, and $10 \%$ for the delivery unit.

However, during this period the C-section tariff did not change in hospitals and remained at $17 \mathrm{~K}$. In addition, with the implementation of the Natural Delivery Promotion Package in hospitals affiliated to MoHME, the private sector hospitals and social security hospitals were also required to reduce their C-section rate; accordingly, the reduction in the rate of $\mathrm{C}$-section was considered as an important factor in their annual accreditation.

The second phase of the HTP was focused on screening chronic diseases and promoting health indicators in rural and marginalized areas and in the suburbs of large cities, and started in June 2014. The second phase is not related to the current study.

In the third phase of HTP, the new book of health services' valuation was issued and implemented in the health system from October 2014 to set tariffs for medical services and promote equality in various medical specialties. To implement the third phase, there was an increase in medical services tariffs in all sectors (public, private, and quasi-public). During this phase, the relative tariffs for vaginal delivery service and C-section service, respectively, were set at $50 \mathrm{~K}$ and $40 \mathrm{~K}(18,21)$.

Given the elimination of costs for natural childbirth in hospitals affiliated to MoHME, requiring hospitals to reduce the number of $\mathrm{C}$-sections, and increasing the tariffs for normal delivery, it is expected to observe changes in the behaviour of mothers and health service providers in choosing natural delivery. In the current study, the immediate and long-term effects of HTP are investigated on the rate of C-section in hospitals affiliated to MoHME (university hospitals) and those not affiliated to MoHME Social Security and private sector hospitals) in Kurdistan province. The results of this study can provide feedback to healthcare policy-makers to assess the success of HTP and revise health reforms in order to enhance them.

\section{Methods}

The HTP (intervention) was implemented in May 2014. We conducted an interrupted time series (ITS) study and analysed monthly $\mathrm{C}$-section rate to assess immediate and long-term effects of HTP on C-section rate in all hospitals affiliated to MoHME and hospitals not affiliated to MoHME in Kurdistan province (Table 1). The study was approved by the Ethics Committee of Tehran University of Medical Sciences.

We detected abrupt drops or increases in the $\mathrm{C}$-section rate and investigated gradual changes in trends during the interruption time. An interrupted time series study

\begin{tabular}{|c|c|}
\hline Variable & Number \\
\hline Population & 1524000 (approximately $2 \%$ of Iranian population) \\
\hline Number of cities & 10 \\
\hline Number of hospitals affiliated to MoHME & 12 \\
\hline Number of hospitals not affiliated to MoHME & 3 (2 hospitals affiliated to SSO and one to private sector) \\
\hline
\end{tabular}


does not require a concurrent "control group" to establish a causal link between an intervention and an outcome $(22,23)$. ITS analysis is perhaps the strongest quasiexperimental research design and is particularly useful when a randomized trial is not feasible or unethical $(23,24)$. Using hospitals' health information systems we obtained the data on deliveries. We modeled data using segmented regressions to assess causal links between the intervention were and the outcome of interest. Our sample included 50 observations (i.e., one per month) starting 25 months before (March 2012 to April 2014) and 24 months after the HTP (June 2014 to May 2016).

Several diagnostic tests were conducted. The results of Dickey-Fuller test suggested the presence of stationary residuals. We estimated the JarqueBerastatistic to check the normality of the residuals. The results suggested a normal residual distribution. We performed ITS analysis using Newey OLS regressionbased approaches available in the official Stata package. The Newey estimates the coefficients by OLS regression, but in addition to possible heteroskedasticity, it presents Newey-West standard errors to handle autocorrelation (25). First, the model was estimated using Newey with lag (o). To ensure the estimation of a model that accounts for the correct autocorrelation structure, we used Actest, lag (6) to investigate autocorrelation. Based on the output table, there was an autocorrelation of error terms at lag $4(P=0.039)$ and lag $1(P=0.016)$ in $C$-section rate data in hospitals affiliated to MoHME and hospitals not affiliated to MoHME, respectively.

Thus, our initial model was adjusted with lag (4) and lag (1) to account for this autocorrelation. The standard ITSA regression model was formed as follows:

$\mathrm{Yt}=\beta \mathrm{o}+\beta$ 1timet $+\beta$ 2interventiont $+\beta 3$ time after intervention (1)

In equation 1, Yt is C-section rate per month; time is a continuous variable indicating time in months at time $\mathrm{t}$ from the start of the observation period; intervention is an indicator for time t occurring before (intervention $=0$ ) or after (intervention =1) the HTP, which was implemented at the 26th month in the series, and time after intervention is counting the number of months after the HTP at time $t ; \beta$ o represents the intercept, or starting level of the outcome variable; $\beta 1$ is the slope, or trajectory of the outcome variable until the introduction of the intervention. $\beta 2$ represents the change in the level of the outcome that occurs in the period immediately following the introduction of the intervention (compared to the counterfactual); $\beta 3$ represents the difference between preand post-intervention slopes of the outcome. The sum of $\beta 1$ and $\beta 3$ is the post-intervention slope. Thus, we look for significant $P$-values in $\beta 2$ to indicate an immediate treatment effect, or in $\beta 3$ to indicate a treatment effect over time $(24,25)$. Analyses were conducted using STATA statistical software version 13 .

\section{Results}

Table 2 reports the total number of deliveries and C-section rate in all hospitals from March 2012 to May 2016.
As shown in the regression table (Table 3), the starting level of C-section rate in the hospitals affiliated to MoHME was estimated to be 0.3716 , and C-section rate appeared to significantly increase by 0.001 every month prior to May 2014 ( $P$ < 0.05). Right after the intervention (HTP) C-section rate (level) significantly decreased by $0.0629(P<0.05)$. However, we did not observe any significant decrease in the regression slope (Trend) $(P>0.05)$. In addition, after the introduction of HTP, post-trend of $\mathrm{C}$-section rate decreased monthly, but the decrease was not significant $(P>0.05)$ (Table 3$)$. The regression model for $\mathrm{C}$-section rate in the hospitals affiliated to MoHME is shown in equation 2 :

$\mathrm{Yt}=0.37159+0.00104$ timet -0.06288 interventiont-0.00118 time after interventiont (2)

Figure 1 presents the visual display of these results.

As shown in the regression table, the starting level of $\mathrm{C}$-section rate in the hospitals not affiliated to MoHME was 0.3783 ; the $\mathrm{C}$-section rate significantly increased by 0.0013 before the intervention $(P<0.05)$. Moreover, we observed a significant decrease by 0.0311 in the intercept right after the initiation of the intervention $(P<0.05)$. However, we did not observe any significant change in the regression slope after the intervention $(P>0.05)$. The post-intervention slope of the $\mathrm{C}$-section rate increased monthly, but this increase was not significant $(P>0.05)$. The regression model for $\mathrm{C}$-section rate in the hospitals not affiliated to MoHME is shown in equation 3:

$\mathrm{Yt}=0.37831+0.0013$ timet -0.0314 interventiont-0.0011 time after interventiont (3).

Figure 2 provides a visual display of these results.

\section{Discussion}

When a patient is receiving healthcare services delivered by healthcare providers, one of the important issues that cannot be neglected is the cost of the services. Altering the costs of different services and changing the reimbursement system can have an impact on healthcare providers' policies and decision, and consequently the C-section rate may change in turn $(16,17)$. Therefore, it is necessary to assess the reimbursement system and other factors that can alter the rate of caesarean delivery. In the current study, we evaluated the effects of the HTP on C-section rate in the Islamic Republic of Iran.

The implementation of HTP significantly decreased the level (immediate effect) of $\mathrm{C}$-section rate in the hospitals affiliated to MoHME. The reduction observed in the hospitals affiliated to MoHME may be due to the elimination of costs of natural delivery (to encourage pregnant women to choose natural delivery), utilizing promotional tariffs for physicians to perform vaginal delivery (after the implementation of the first phase, a promotional tariff of $30 \mathrm{~K}$ was added to the natural delivery tariff in hospitals affiliated to MoHME), and increasing the tariff of natural delivery within the new book of tariffs published in the third phase (the tariff of natural delivery was increased to 50K) (18). Despite the two years since the beginning of the HTP, the elimination 


\begin{tabular}{|c|c|c|c|c|c|c|c|}
\hline Observation & $\begin{array}{l}\text { Total number } \\
\text { of deliveries } \\
\text { in hospitals } \\
\text { affiliated to } \\
\text { MoHME }\end{array}$ & $\begin{array}{l}\text { C-section rate } \\
\text { in hospitals } \\
\text { affiliated to } \\
\text { MoHME }\end{array}$ & $\begin{array}{l}\text { Total number } \\
\text { of deliveries in } \\
\text { hospitals not } \\
\text { affiliated to } \\
\text { MoHME }\end{array}$ & $\begin{array}{l}\text { C-section rate } \\
\text { in hospitals not } \\
\text { affiliated to } \\
\text { MoHME }\end{array}$ & Time (Month) & Intervention & $\begin{array}{c}\text { Time after } \\
\text { intervention }\end{array}$ \\
\hline 1 & 1947 & 0.370827 & 400 & 0.3875 & 1 & 0 & 0 \\
\hline 2 & 1890 & 0.37037 & 401 & 0.40399 & 2 & 0 & 0 \\
\hline 3 & 1962 & 0.365953 & 426 & 0.401408 & 3 & 0 & 0 \\
\hline 4 & 2031 & 0.360414 & 378 & 0.383598 & 4 & 0 & 0 \\
\hline 5 & 1994 & 0.361083 & 377 & 0.366048 & 5 & 0 & 0 \\
\hline 6 & 2009 & 0.383275 & 395 & 0.36962 & 6 & 0 & 0 \\
\hline 7 & 1769 & 0.384398 & 436 & 0.401376 & 7 & 0 & 0 \\
\hline 8 & 1781 & 0.400898 & 396 & 0.40404 & 8 & 0 & 0 \\
\hline 9 & 1694 & 0.401417 & 407 & 0.361179 & 9 & 0 & 0 \\
\hline 10 & 1846 & 0.385699 & 417 & 0.364508 & 10 & 0 & 0 \\
\hline 11 & 1889 & 0.390683 & 452 & 0.393805 & 11 & 0 & 0 \\
\hline 12 & 1843 & 0.398264 & 390 & 0.364103 & 12 & 0 & 0 \\
\hline 13 & 1979 & 0.376453 & 441 & 0.390023 & 13 & 0 & 0 \\
\hline 14 & 1834 & 0.377317 & 469 & 0.415778 & 14 & 0 & 0 \\
\hline 15 & 1956 & 0.380368 & 503 & 0.379722 & 15 & 0 & 0 \\
\hline 16 & 1990 & 0.38794 & 519 & 0.400771 & 16 & 0 & 0 \\
\hline 17 & 2013 & 0.398907 & 482 & 0.400415 & 17 & 0 & 0 \\
\hline 18 & 1968 & 0.412602 & 505 & 0.415842 & 18 & 0 & 0 \\
\hline 19 & 1711 & 0.374635 & 453 & 0.415011 & 19 & 0 & 0 \\
\hline 20 & 1806 & 0.379845 & 485 & 0.416495 & 20 & 0 & 0 \\
\hline 21 & 1909 & 0.387114 & 417 & 0.407674 & 21 & 0 & 0 \\
\hline 22 & 2056 & 0.375486 & 441 & 0.414966 & 22 & 0 & 0 \\
\hline 23 & 2017 & 0.392662 & 500 & 0.416 & 23 & 0 & 0 \\
\hline 24 & 2061 & 0.402717 & 295 & 0.40339 & 24 & 0 & 0 \\
\hline 25 & 2048 & 0.408691 & 336 & 0.401786 & 25 & 0 & 0 \\
\hline 26 & 2070 & 0.384541 & 363 & 0.396694 & 26 & 1 & 1 \\
\hline 27 & 2049 & 0.367496 & 458 & 0.40393 & 27 & 1 & 2 \\
\hline 28 & 2155 & 0.342459 & 475 & 0.383158 & 28 & 1 & 3 \\
\hline 29 & 2088 & 0.314176 & 474 & 0.405063 & 29 & 1 & 4 \\
\hline 30 & 2126 & 0.326435 & 502 & 0.386454 & 30 & 1 & 5 \\
\hline 31 & 1961 & 0.319225 & 384 & 0.372396 & 31 & 1 & 6 \\
\hline 32 & 1941 & 0.308089 & 433 & 0.385681 & 32 & 1 & 7 \\
\hline 33 & 1979 & 0.331481 & 385 & 0.366234 & 33 & 1 & 8 \\
\hline 34 & 2044 & 0.327299 & 455 & 0.397802 & 34 & 1 & 9 \\
\hline 35 & 2153 & 0.337204 & 479 & 0.363257 & 35 & 1 & 10 \\
\hline 36 & 2044 & 0.34002 & 334 & 0.362275 & 36 & 1 & 11 \\
\hline 37 & 2210 & 0.333937 & 341 & 0.360704 & 37 & 1 & 12 \\
\hline 38 & 2399 & 0.300959 & 382 & 0.363874 & 38 & 1 & 13 \\
\hline 39 & 2326 & 0.322872 & 452 & 0.360619 & 39 & 1 & 14 \\
\hline 40 & 2336 & 0.318493 & 424 & 0.360849 & 40 & 1 & 15 \\
\hline 41 & 2402 & 0.336803 & 413 & 0.377724 & 41 & 1 & 16 \\
\hline 42 & 2282 & 0.339176 & 469 & 0.394456 & 42 & 1 & 17 \\
\hline 43 & 2008 & 0.318227 & 426 & 0.396714 & 43 & 1 & 18 \\
\hline 44 & 1916 & 0.336117 & 322 & 0.378882 & 44 & 1 & 19 \\
\hline 45 & 1917 & 0.3229 & 383 & 0.391645 & 45 & 1 & 20 \\
\hline 46 & 2094 & 0.346227 & 419 & 0.396181 & 46 & 1 & 21 \\
\hline 47 & 2040 & 0.347059 & 435 & 0.393103 & 47 & 1 & 22 \\
\hline 48 & 2072 & 0.343147 & 336 & 0.39881 & 48 & 1 & 23 \\
\hline 49 & 2211 & 0.341927 & 358 & 0.396648 & 49 & 1 & 24 \\
\hline 50 & 2069 & 0.343644 & 333 & 0.393393 & 50 & 1 & 25 \\
\hline
\end{tabular}


Table 3 Estimated coefficients of segmented regression model for C-section rate in the hospitals affiliated to MoHME in Kurdistan province, March 2012-May 2016

\begin{tabular}{|c|c|c|c|c|c|c|}
\hline \multicolumn{7}{|c|}{ Regression with Newey-Weststandard errors } \\
\hline \multirow{2}{*}{$\begin{array}{l}\text { Maximum lag: } 4 \\
\text { Parameter }\end{array}$} & \multicolumn{2}{|c|}{ Number of observations $=\mathbf{5 0}$} & \multicolumn{2}{|c|}{$F(3,46)=45.29$} & \multicolumn{2}{|c|}{ Prob $>$ F $=0.0000$} \\
\hline & Coefficients & Newey-West Std. Err. & $\mathbf{t}$ & P-value & & \\
\hline Intercept & 0.37159 & 0.0066 & 56.44 & 0.000 & 0.3583 & 0.3849 \\
\hline Pre-intervention slope & 0.00104 & 0.0004 & 2.67 & 0.010 & 0.0003 & 0.0018 \\
\hline Change in intercept & -0.06288 & 0.0126 & -4.98 & 0.000 & -0.0883 & -0.0375 \\
\hline Change in slope & -0.00118 & 0.0010 & -1.22 & 0.230 & -0.0031 & 0.0008 \\
\hline $\begin{array}{l}\text { Post-intervention Linear } \\
\text { Trend }\end{array}$ & -0.00010 & 0.0008 & -0.17 & 0.860 & -0.0018 & 0.0011 \\
\hline
\end{tabular}

of costs of natural childbirth for mothers, and increasing the tariffs of natural delivery for medical personnel, the rate of C-section in hospitals affiliated to MoHME in Kurdistan province still varies considerably with the standard rate recommended by WHO. There is no significant reduction in the slope of $\mathrm{C}$-section in this group of hospitals.

The implementation of HTP significantly decreased the level (immediate effect) of C-section rate in nonuniversity hospitals. The decrease in C-section observed in hospitals not affiliated to MoHME may be attributed to the fact that the hospitals were obliged (by Kurdistan University of Medical Sciences) to reduce their rates of C-section during the implementation of the HTP. As ordered by MoHME, non-university hospitals must decrease their rate of C-section by $10 \%$ annually, as compared with the baseline; the reduction will be considered as a factor in their annual accreditation (18).

The results of a study by Kim et al. in the Republic of Korea suggested that the type of the reimbursement system was associated with higher probability of $\mathrm{C}$-section. To reduce the rate of caesarean delivery in the Republic of Korea, the payment method for caesarean delivery changed from Fee-For-Services (FFS) to Diagnostic Related Groups (DRG) and the tariff of natural delivery was increased by 50\%. After taking these measures, the rate of $\mathrm{C}$-section was significantly reduced (17). In line with the results of previous studies, the results of the current study indicated that women's decision to undergo C-section is affected by the related costs $(10,26,27)$. However, some studies found no relationship between the costs of the procedure and women's decision to undergo C-section $(28,29)$. For example, the results of a study by Lo in Taiwan (29) showed that the policy of fee equalization for vaginal and caesarean deliveries had no influence. Accordingly, as decided by the National Health Insurance (NHI) in Taiwan, the costs of vaginal birth and $\mathrm{C}$-section were equalized. In an insurance

Figure 1 Segmented regression model showing C-section rate in the hospitals affiliated to MoHME in Kurdistan province, March 2012 to May 2016

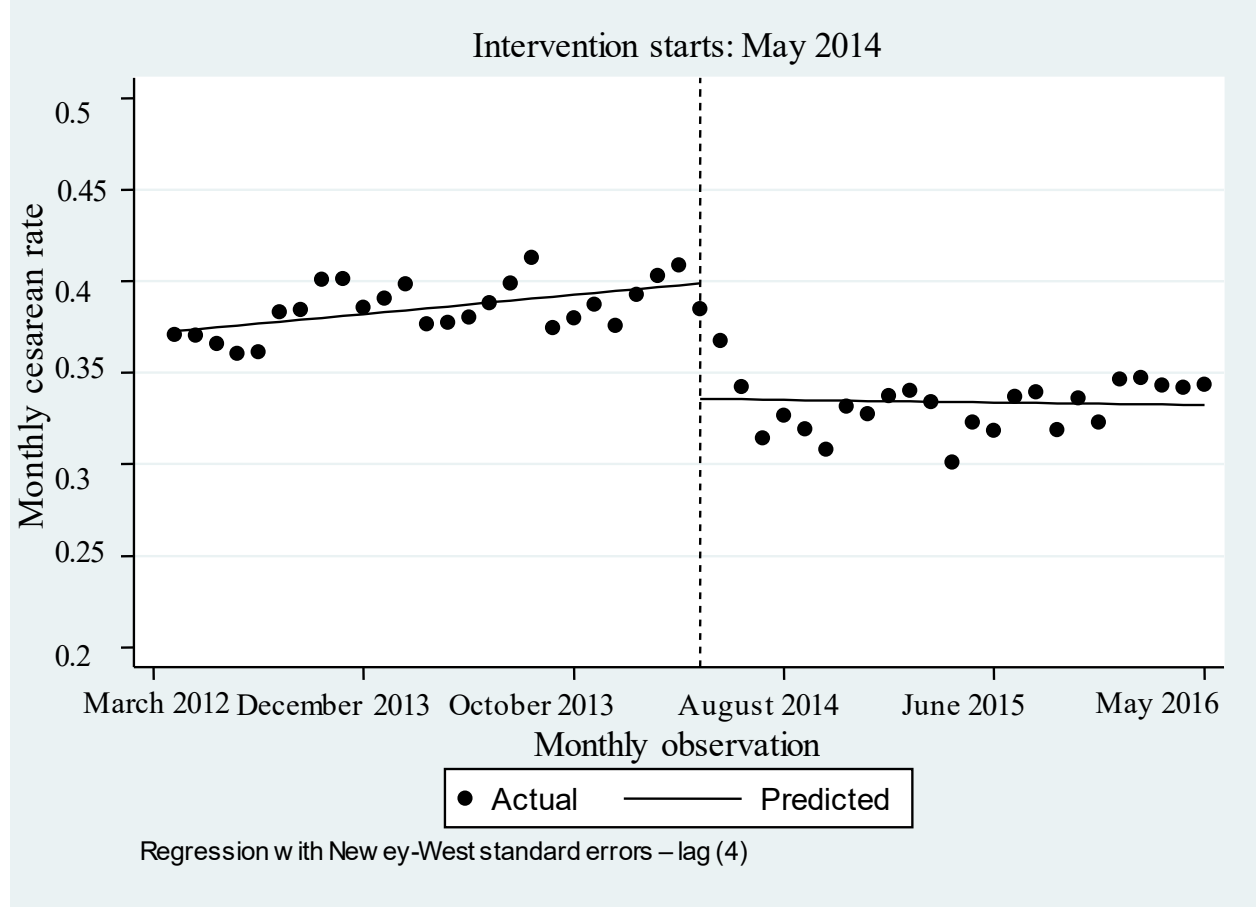


Figure 2 Segmented regression model showing C-section rate in the hospitals not affiliated to MOHME, in Kurdistan province, March 2012 to May 2016

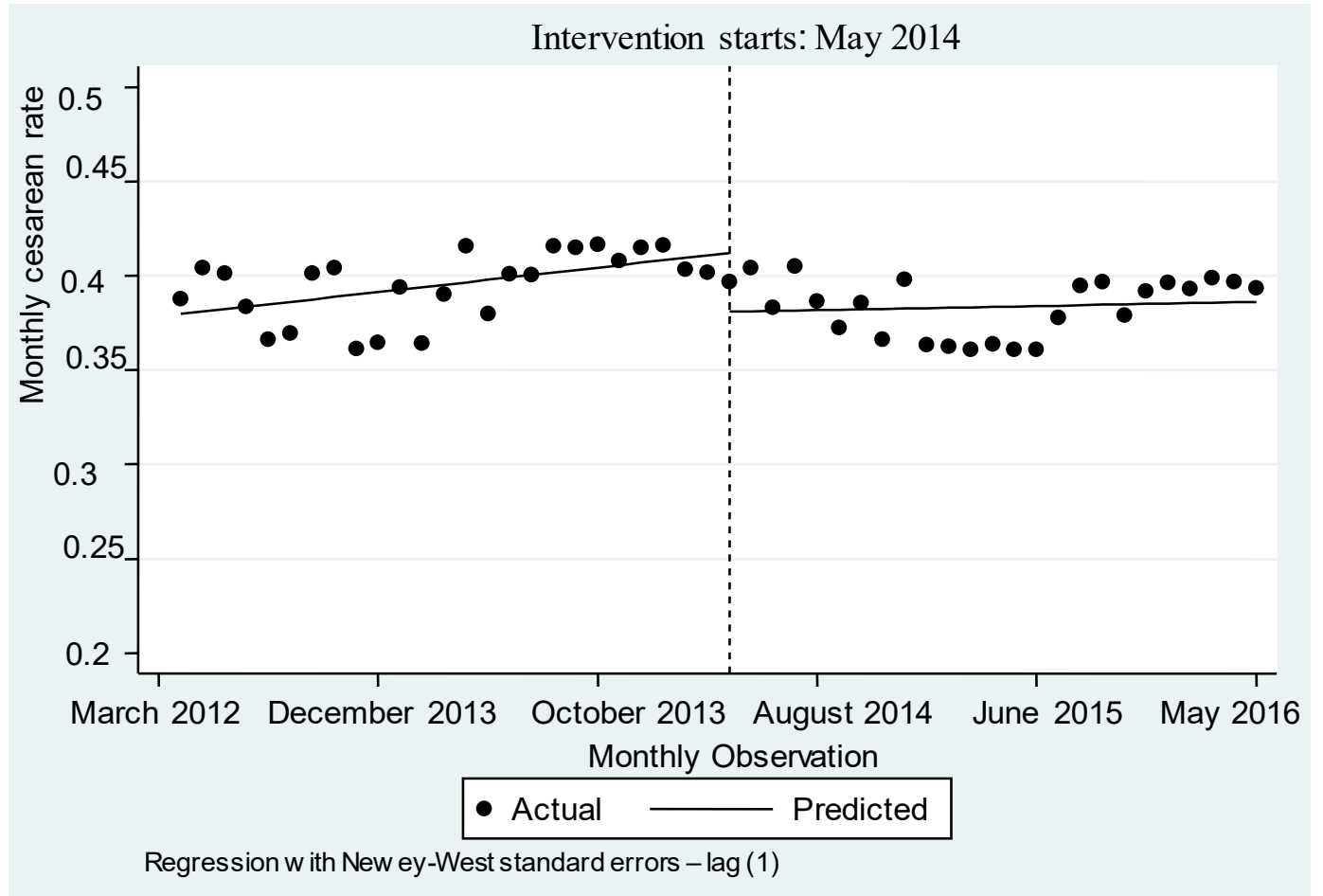

reform in California, United States, the costs of vaginal and caesarean deliveries had been equalized, as studied by Keeler and Fok (28). Based on the results of their study, after adjusting for case-mix, there was an insignificant reduction (0.7\%) in C-section rate after the reform (28).

The current study aimed to assess the impact of HTP on the rate of C-section; however, it did not consider the effects of birth order and previous caesarean, and these two factors might have an impact on interventions utilized in HTP and on the rate of C-section. Studies have shown that most mothers who already had had a caesarean delivery are forced to undergo a caesarean again in subsequent pregnancies (29). According to the results of a study in Taiwan (29), the rate of C-section increased with the birth order, rising from $29 \%$ in the first birth to $37.4 \%$ in the second birth and $39.3 \%$ in the third birth. This observation was mainly attributed to the previous history of C-section, where the primary rates were $29 \%, 11.8 \%$, and $12.1 \%$, respectively. In that study the increasing fee for vaginal deliveries did not influence the C-section rate (29). However, based on our findings, cost has an impact on the choice made by physicians and patients for a specific medical procedure.

\section{Limitations}

This study was carried out in Kurdistan province in the west of the Islamic Republic of Iran; hence, the results may not represent a full picture of the impact of HTP on $\mathrm{C}$-section rate across the whole country. Moreover, in this study we assessed the effects of HTP on C-section without taking into account the previous $\mathrm{C}$-section and medical risk factors. Given the high rate of $\mathrm{C}$-section in the years before the implementation of HTP in the Islamic Republic of Iran and Kurdistan, it might have reduced (distorted) the real effect of the HTP on the rate of C-section. Thus, further studies are needed to more accurately study this issue at an individual level.

\section{Conclusion}

In general, based on the results of this study, after the implementation of HTP the rate of C-section was significantly reduced in Kurdistan province; however, the reduction observed was less than the expected level. The rate of C-section in Kurdistan province is still significantly higher than the standard rate recommended by WHO. Apparently, in order to further reduce the rate of C-section it is necessary not only to promote financial incentives for mothers and health service providers, but also focus on policies to change mothers' choice behaviours through awareness-raising programmes on natural childbirth and the negative consequences of C-section. However, our study has provided some evidences for policy-makers and suggests that health providers are under the influence of the existing reimbursement system. Accordingly, healthcare providers' decisions on the mode of delivery might be largely influenced by economic factors and advantages. As a result, it is necessary to design and adopt proper strategies for reimbursement in order to decrease the rate of superfluous procedures.

Funding: This research was funded by the Kurdistan University of Medical Sciences (no. 1395.381).

Competing interests: None declared. 


\section{Effets du plan national de transformation du secteur de la santé sur le taux de césarienne en République islamique d'Iran : série chronologique interrompue}

\section{Résumé}

Contexte: Au cours des dernières décennies, on a observé une augmentation du taux de césarienne en République islamique d'Iran. Une réforme du système de santé iranien - le plan national de transformation du secteur de la santé - a été lancée en 2014. L'un des objectifs de ce plan vise à réduire le taux de césarienne.

Objectifs : La présente étude vise à évaluer les effets du plan national de transformation du secteur de la santé sur le taux de césarienne en République islamique d'Iran.

Méthodes : La présente étude constitue une analyse d'une série chronologique interrompue basée sur une analyse de régression segmentée afin d'évaluer les effets immédiats et à long terme du plan de transformation du secteur de la santé sur le taux de césarienne dans deux groupes d'hôpitaux affiliés et non affiliés au ministère de la Santé et de l'Éducation médicale dans la province du Kurdistan. Les échantillons de l'étude ont été choisis en utilisant les données relatives au taux mensuel de césariennes, collectées sur une période de quatre ans.

Résultats : Nous avons observé une diminution sensible du taux de césarienne immédiatement après la mise en place du plan de transformation du secteur de la santé dans les deux groupes d'hôpitaux, s'élevant respectivement à 0,0629 et $0,0013,(\mathrm{p}<0,05)$. À long terme, nous n'avons observé aucune diminution importante de la pente de régression du taux de césarienne dans les deux groupes.

Conclusions : La mise en œuvre de ce plan de transformation du secteur de la santé a permis de diminuer le taux de césarienne. Cependant, cette réduction est en deçà des attentes.

$$
\begin{aligned}
& \text { آثار خطة التحوُّل الصحي على معدل الجر احات القيصرية في جمهورية إيران الإسلامية: سلسلة زمنية متقطعة }
\end{aligned}
$$

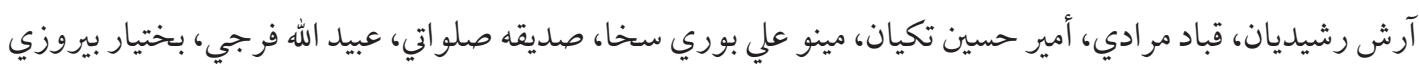

الخلفية: في العقود الأخيرة، ارتفع معدل الجراحات القيصرية في جمهورية إيران الإسلامية. وبدأ إصلاح نظام الصحة الإيراني -خطة التحوُّل

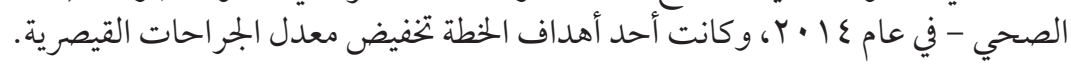

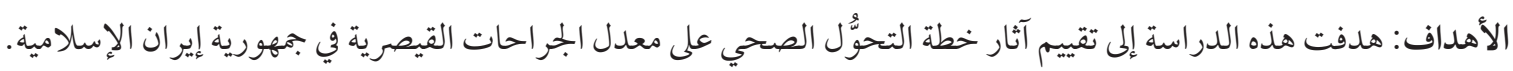

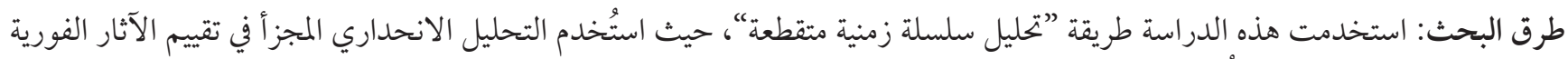

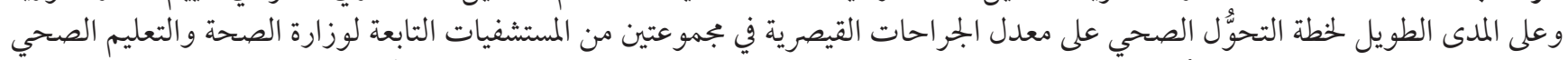

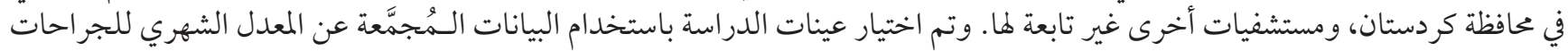

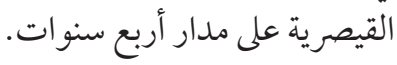

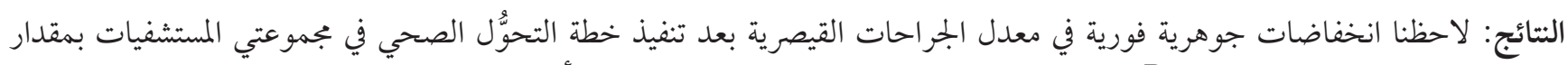

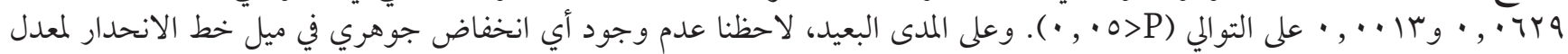
الجراحات القيصرية في كلا المجموعتين. الاستنتاجات: أدى تنفيذ خطة التحوُّل الصحي إلى تخفيض معدل الجرات احات القيصرية. ومع ذلك، لم يجقّق الانخفاض التوقعات المأمولة.

\section{References}

1. Bahadori F, Hakimi S, Heidarzade M. The trend of caesarean delivery in the Islamic Republic of Iran/Évolution des accouchements par césarienne en République islamique d'Iran. East Mediterr Health J. 2013;19(2):1.

2. Azami-Aghdash S, Ghojazadeh M, Dehdilani N, Mohammadi M, Abad RAA. Prevalence and Causes of Cesarean Section in Iran: Systematic Review and Meta-Analysis. Iran J Public Health. 2014;43(5):545-55.

3. Stanton CK, Holtz SA. Levels and trends in cesarean birth in the developing world. Stud FamPlann. 2006;37(1):41-8. http://dx.doi. $\operatorname{org} / 10.1111 /$ j.1728-4465.2006.00082.x

4. Ahmad Nia S, Delavar B, EiniZinab H, Kazemipour S, Mehryar A, Naghavi M. Caesarean section in the Islamic Republic of Iran: prevalence and some sociodemographic correlates. East Mediterr Health J. 2009 Nov-Dec;15(6):1389-98 PMID: 20218129

5. Yazdizadeh B, Nedjat S, Mohammad K, Rashidian A, Changizi N, Majdzadeh R. Cesarean section rate in Iran, multidimensional approaches for behavioral change of providers: a qualitative study. BMC Health Serv Res. 2011;11(1):159. http://dx.doi. org/10.1186/1472-6963-11-159 
6. Burns LR, Geller SE, Wholey DR. The effect of physician factors on the cesarean section decision.Med Care. 1995;33(4):365-82. http://dx.doi.org/10.1097/00005650-199504000-00004

7. Coco AS, Gates TJ, Gallagher ME, Horst MA. Association of attending physician specialty with esarean delivery rate in the same patient population. Family Med. 2000;32(9):639-44. PMID: 11039152

8. Dubay L, Kaestner R, Waidmann T. The impact of malpractice fears on cesarean section rates. J Health Econ. 1999;18(4):491-522. http://dx.doi.org/10.1016/S0167-6296(99)00004-1

9. Tussing AD, Wojtowycz MA. Malpractice, defensive medicine, and obstetric behavior.Med Care. 1997;35(2):172-91. http://dx.doi. org/10.1097/00005650-199702000-00007

10. Gruber J, Kim J, Mayzlin D. Physician fees and procedure intensity: the case of cesarean delivery. J Health Econ. 1999;18(4):47390. http://dx.doi.org/10.1016/S0167-6296(99)00009-0

11. Tollånes MC, Thompson JM, Daltveit AK, Irgens LM. Cesarean section and maternal education; secular trends in Norway, 1967-2004.ActaObstetGynecol Scand. 2007;86(7):840-8. http://dx.doi.org/10.1080/00016340701417422

12. Gould JB, Davey B, Stafford RS.Socioeconomic differences in rates of cesarean section. N Engl J Med. 1989;321(4):233-9. http:// dx.doi.org/10.1056/NEJM198907273210406

13. Gibbons L, Belizán JM, Lauer JA, Betrán AP, Merialdi M, Althabe F. The global numbers and costs of additionally needed and unnecessary caesarean sections performed per year: overuse as a barrier to universal coverage. World Health Rep. 2010;30:1-31.

14. Lin H-C, Xirasagar S. Maternal age and the likelihood of a maternal request for cesarean delivery: a 5-year population-based study. Am J Obstet Gynecol. 2005;192(3):848-55. http://dx.doi.org/10.1016/j.ajog.2004.09.133

15. Weiss JL, Malone FD, Emig D, Ball RH, Nyberg DA, Comstock CH, et al. Obesity, obstetric complications and cesarean delivery rate-a population-based screening study. Am J Obstet Gynecol. 2004;190(4):1091-7. http://dx.doi.org/10.1016/j.ajog.2003.09.058

16. Arrieta A. Health reform and cesarean sections in the private sector: the experience of Peru. Health Policy. 2011;99(2):124-30. http://dx.doi.org/10.1016/j.healthpol.2010.07.016

17. Kim SJ, Han K-T, Kim SJ, Park E-C, Park HK.Impact of a diagnosis-related group payment system on cesarean section in Korea. Health Policy. 2016;120(6):596-603. http://dx.doi.org/10.1016/j.healthpol.2016.04.018

18. Piroozi B, Moradi G, EsmailNasab N, Ghasri H, Farshadi S, Farhadifar F. Evaluating the effect of health sector evolution plan on cesarean rate and the average costs paid by mothers: A case study in Kurdistan province between 2013-2015. Journal of hayat. 2016;22(3):245-54.

19. Asefzadeh S, Rezapour A. Health management. Qazvin university of Medical Sciences publication. Persian; 2011:100-1.

20. Khabiri R, Khosravi A, Elahi E. KhodayariMoez, Rashidian A. Maternal Health Care based on Iran' Multiple Indicator Demographic and Health Survey (IrMIDHS-2010). Hakim Health Sys Res. 2014;17(1):67-77.

21. Piroozi B, Rashidian A, Moradi G, Takian A, Ghasri H, Ghadimi T. Out-of-Pocket and Informal Payment Before and After the Health Transformation Plan in Iran: Evidence from Hospitals Located in Kurdistan, Iran. Int J Health Policy Manag. 2017;6(10):573-86. http://dx.doi.org/ 10.15171/ijhpm.2017.16

22. Rashidian A, Joudaki H, Khodayari-Moez E, Omranikhoo H, Geraili B, Arab M. The impact of rural health system reform on hospitalization rates in the Islamic Republic of Iran: an interrupted time series. Bull World Health Organ. 2013;91(12):942-9. http:// dx.doi.org/10.2471/BLT.12.111708

23. Cook TD, Campbell DT, Day A. Quasi-experimentation: Design \& analysis issues for field settings: Houghton Mifflin Boston; 1979.

24. Wagner AK, Soumerai SB, Zhang F, Ross-Degnan D. Segmented regression analysis of interrupted time series studies in medication use research. J Clin Pharm Ther. 2002;27(4):299-309. http://dx.doi.org/10.1046/j.1365-2710.2002.00430.x

25. Linden A. Conducting interrupted time-series analysis for single-and multiple-group comparisons. Stata J. 2015;15(2):480-500.

26. Grant D. Physician financial incentives and cesarean delivery: new conclusions from the healthcare cost and utilization project. J Health Econ. 2009;28(1):244-50. http://dx.doi.org/10.1016/j.jhealeco.2008.09.005

27. Allen VM, O'connell CM, Farrell SA, Baskett TF. Economic implications of method of delivery. Am J Obstet Gynecol. 2005;193(1):192-7. http://dx.doi.org/10.1016/j.ajog.2004.10.635

28. Keeler EB, Fok T. Equalizing physician fees had little effect on cesarean rates. Med Care Res Rev. 1996;53(4):465-71. http://dx.doi. org/10.1177/107755879605300405

29. Lo JC. Financial incentives do not always work-an example of cesarean sections in Taiwan. Health Policy. 2008;88(1):121-9. http://dx.doi.org/10.1016/j.healthpol.2008.02.013

30. MoradiGh, Piroozi P, Safari H. N E-N, Yari Y, Mohamadi-Bolbanabad A. Assessment of the efficiency of hospitals before and after the implementation of the health sector evolution plan in Iran based on Pabon Lasso Model. Iran J Public Health. 2017 Mar;46(3):389-395 PMID: 28435825 